\title{
Sultr4;1 mutant seeds of Arabidopsis have an enhanced sulphate content and modified proteome suggesting metabolic adaptations to altered sulphate compartmentalization
}

\author{
Hélène Zuber*1, Jean-Claude Davidian², Markus Wirtz³ , Rüdiger Hell ${ }^{3}$, Maya Belghazi ${ }^{4}$, Richard Thompson ${ }^{1}$ and \\ Karine Gallardo'
}

\begin{abstract}
Background: Sulphur is an essential macronutrient needed for the synthesis of many cellular components. Sulphur containing amino acids and stress response-related compounds, such as glutathione, are derived from reduction of root-absorbed sulphate. Sulphate distribution in cell compartments necessitates specific transport systems. The lowaffinity sulphate transporters SULTR4;1 and SULTR4;2 have been localized to the vacuolar membrane, where they may facilitate sulphate efflux from the vacuole.

Results: In the present study, we demonstrated that the Sultr4;1 gene is expressed in developing Arabidopsis seeds to a level over 10-fold higher than the Sultr4;2 gene. A characterization of dry mature seeds from a Sultr4; 1 T-DNA mutant revealed a higher sulphate content, implying a function for this transporter in developing seeds. A fine dissection of the Sultr4;1 seed proteome identified 29 spots whose abundance varied compared to wild-type. Specific metabolic features characteristic of an adaptive response were revealed, such as an up-accumulation of various proteins involved in sugar metabolism and in detoxification processes.

Conclusions: This study revealed a role for SULTR4; 1 in determining sulphate content of mature Arabidopsis seeds. Moreover, the adaptive response of sultr4; 1 mutant seeds as revealed by proteomics suggests a function of SULTR4;1 in redox homeostasis, a mechanism that has to be tightly controlled during development of orthodox seeds.
\end{abstract}

\section{Background}

In recent decades, sulphur deficiency has become an increasing problem in crops of many countries, notably in Western Europe, leading to sulphur deficiency symptoms and resulting in decreased crop yields and quality parameters [1-3]. In this context, sulphur acquisition and metabolism in plants has become a major concern for research and crop improvement. Sulphur is an essential macronutrient required for plant growth. It is mainly acquired by the plant roots as inorganic sulphate and then distributed within the tissues [4]. After entering the cells, sulphate is reduced to sulphide with any excess sulphate being stored in the vacuole [5-7]. Sulphate assimila-

\footnotetext{
* Correspondence: helene.zuber@dijon.inra.fr

1 UMR102 Genetics and Ecophysiology of Grain legumes, INRA, F-21000 Dijon, France
}

Full list of author information is available at the end of the article tion leads to the synthesis of many compounds, including sulphur amino acids (cysteine and methionine), secondary products (glucosinolates and flavonoids) and numerous essential metabolites derived from sulphurcontaining amino acids, such as cofactors (e.g. glutathione, $S$-adenosylmethionine, coenzyme A) and vitamins (e.g. biotin and thiamine). Therefore, sulphur assimilation is an essential part of plant metabolism and plays a crucial role in many plant processes. For example, as part of glutathione, sulphur has a role in the maintenance of the cellular redox balance and mitigation of oxidative stress in response to environmental changes. Furthermore, as constituent of sulphur amino acids, sulphur is tightly connected to protein synthesis and metabolism and is of great importance in terms of nutritional value. Indeed, animals and humans are unable to synthesize 
methionine and are dependent on dietary sources of this amino acid. Seeds of many agronomically important crops, including grain legumes, while rich in proteins, are deficient in the sulphur amino acids. Tabe and Droux [8] demonstrated that sulphate is the dominant form of sulphur found in the phloem supplying pods during lupin seed development and that the seed is able to reduce and assimilate sulphate in sufficient quantities for its needs. Therefore, identifying the mechanisms involved in sulphate acquisition and distribution in the developing seed is relevant to seed quality improvement.

The movement of sulphate around the plant and between cell compartments is facilitated by specific sulphate transporters (SULTR), which are encoded by a large gene family, consisting of 14 members in Arabidopsis and rice. Phylogenetic analyses indicate this gene family can be divided into four closely related groups (SULTR1 to 4) each with 12 membrane-spanning domains and a STAS (Sulphate Transporter and Anti-sigma Antagonist) domain at the carboxy-terminus [9], and a fifth more distinct group, SULTR5, lacking the STAS domain [4]. Notably, the Arabidopsis Sultr5;2 gene has recently been demonstrated to encode a high-affinity root molybdate transporter [10], which raises the question of the role of group 5 genes in sulphate transport. Considering differences in their kinetics and expression patterns, the different groups have been proposed to represent functional subtypes [11,12]. Group 1 and 2 sulphate transporters, which are localised at the plasma membrane, have been the subject of several studies and are the best characterized groups. Members of group 1 represent high-affinity transporters that facilitate uptake of sulphate by the root (SULTR1;1 and SULTR1;2) or translocation of sulphate from source-to-sink organs (SULTR1;3) [13-17]. Group 2 is composed of low-affinity sulphate transporters whose gene products may rather play a role in vascular tissues, faciliting the translocation of sulphate around the plant [[4,14] and [18]]. Group 3 is composed of low affinity transporters localized at the plasma membrane. The data available in the litterature indicate a differential expression of these genes in plant tissues, which is not stimulated by sulphur deficiency [19], and a role for SULTR3;5 in the root-to-shoot transport of sulphate in cooperation with SULTR2;1 in Arabidopsis [20].

Unlike groups 1 to 3 , group 4 sulphate transporters have been localized to the vacuolar membrane: a SULTR4;1-GFP fusion protein was specifically accumulated in the vacuoles of roots and hypocotyls from young seedlings [21]. The Sultr4;1 gene was shown to be expressed in roots under sulphur-sufficient and deficient conditions, where it may play a role in the efflux of sulphate from the vacuolar lumen into the cytoplasm and influence the vacuolar storage capacity for sulphate [21]. In contrast, Sultr4;2 gene expression was shown to be highly inducible by sulphur limitation in the same tissue. The sultr4;1/sultr4;2 double knock-out mutants contained higher amounts of sulphate than did wild-type plants. Comparison of single and sultr4;1/sultr4;2 double knock-out mutants suggested that Sultr4;1 plays a major role and Sultr4;2 has a supplementary function [21]. Although sulphate transport has been extensively studied in roots, to date there has been no investigation of the roles of individual sulphate transporters within seeds. The vacuole may certainly play a role in the storage and unloading of sulphate within the developing seed, in which case SULTR4 transporters would be key players.

In this study, we demonstrate that, the Arabidopsis Sultr4;1 gene is strongly expressed in developing seeds and that its disruption significantly increases seed sulphate content, suggesting that SULTR4; 1 is involved in the efflux of sulphate from vacuoles within developing seeds. Furthermore, a proteome analysis of Sultr4;1 mutant seeds reveals metabolic modulations suggesting adaptations to altered sulphate conpartmentation, which implicates SULTR4;1-mediated sulphate transport in establishment of defence mechanisms against oxidative stress during seed development.

\section{Results}

\section{Sultr4; 1 is strongly expressed during seed filling}

We first analysed by Real-Time Quantitative Reverse Transcription-PCR (qRT-PCR) gene expression levels of the Arabidopsis sulphate transporters belonging to group 4 (SULTR4;1 and SULTR4;2) (Figure 1). The analysis was

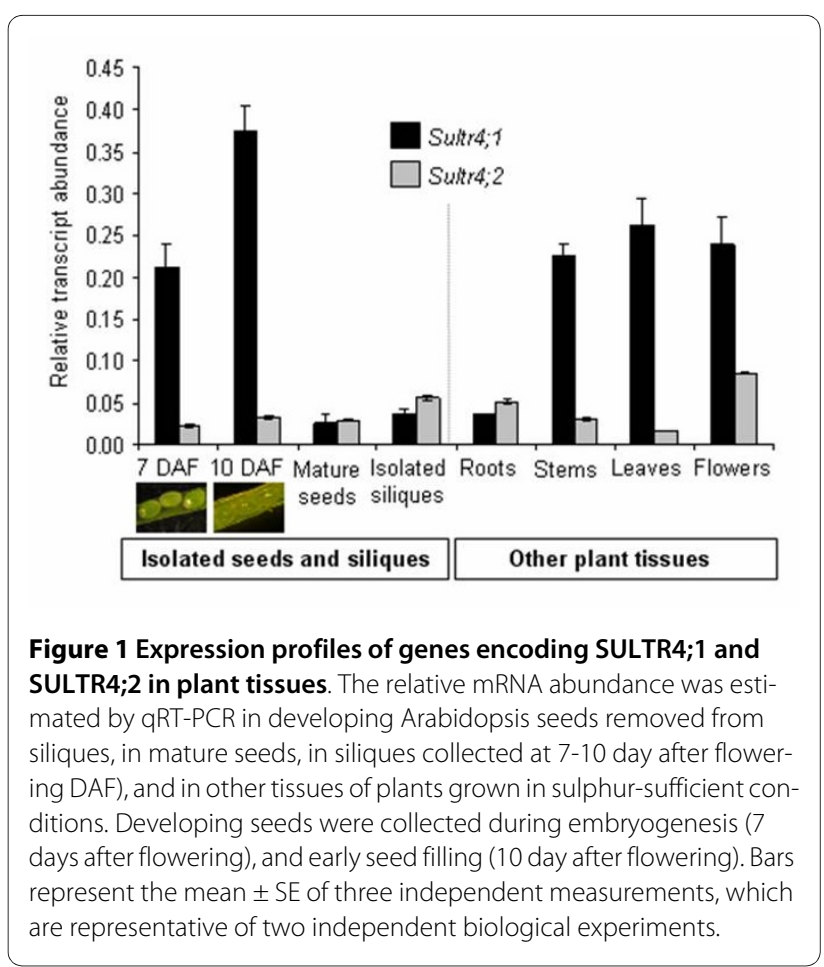


performed on isolated seeds [7 and 10 days after flowering (DAF) corresponding to embryogenesis and seed filling stages, respectively], on isolated siliques (at 7-10 DAF) and for other tissues (leaves, flowers, roots, and stems), all collected during the reproductive growth phase of plants grown under sulphur-sufficient conditions. In addition, we compared qRT-PCR expression profiles by using an available microarray-based transcriptomics dataset ([22], see Additional file 1). The qRT-PCR data were consistent with the microarray dataset, but as commonly observed, the dynamic range of expression was higher with qRT-PCR.

The combined set of expression data (see Figure 1 and Additional file 1) showed an expression of both genes in various plant tissues during reproductive growth, but with different levels and patterning of expression. First, Sultr4;1 was strongly expressed in developing seeds, whereas Sultr4;2 was preferentially expressed in flowers. Second, microarray expression data available for roots of 10-day-old plants subjected to sulphur starvation for $24 \mathrm{~h}$ revealed that the two genes respond differently to a limitation in sulphur supply, Sultr4;1 and Sultr4;2 expression being up-regulated by 1.7 and 3.7 fold, respectively, in these conditions (see Additional file 1). Third, the two genes were differentially expressed during seed development: Sultr4;1 was highly expressed at the onset of seed filling, whereas Sultr4;2 was expressed at almost constitutive levels from embryogenesis to the dry mature stage. Finally, the qRT-PCR data revealed that the Sultr4;1 gene was more highly expressed than Sultr4;2 in most plant organs (Figure 1). Notably, Sultr4;1 was up to 10 -fold more expressed in the isolated developing seeds at 7 and 10 DAF as compared with Sultr4;2, whereas both transcripts were similarly abundant in the isolated siliques at the same stages. These data suggested the SULTR4;1 may have an important function within the developing seed, which had not previously been reported and merited further investigations.

\section{Sulphate content is elevated in SULTR4; 1 mature seeds}

To investigate the role of SULTR4;1 in determining seed sulphate content, we used a sultr4; 1 T-DNA insertion line from the Arabidopsis SALK collection [23]. The T-DNA was located in the STAS domain http://atensembl.arabidopsis.info/index.html critical for both the activity and biosynthesis/stability of sulphate transporters [24]. The presence of the insertion in plants was confirmed by PCR (data not shown). Mature seeds were collected from homozygous mutant plants and from the corresponding wild-type (Columbia, Col-O). Sultr4;1 gene expression was measured by qRT-PCR in mature seeds of wild-type and sultr4;1 mutant plants, from three biological replicates. In the mutant line, the accumulation of the corresponding intact mRNA decreased strongly (94-99\% decrease, see Additional file 2), suggesting that the TDNA insertion altered dramatically transcription and/or mRNA stability.

The profiles and contents of major inorganic and organic anions (sulphate, nitrate, phosphate, chloride, malate and citrate) and the overall sulphur content were determined (Figure 2). Interestingly, in mature sultr4;1 seeds, the average sulphate content was about 1.7 fold higher than that of wild-type (Figure 2a), whereas seed sulphur content was unchanged (Figure $2 \mathrm{~b}$ ). The sulphate form represents a significant fraction of sulphur in mature seeds: $7.7 \%$ and $13.24 \%$ of total sulphur content respectively in wild-type and sultr4;1 mutant seeds. With respect to the sultr4;1 plant phenotype, no significant difference in seed yield, leaf surface, or onset of flowering was observed (Figure 3). Only a slight decrease in sultr4;1 seed weight was observed compared to wild-type (Figure 3c). These data suggest sulphur flux into developing seeds may not be affected in sultr4;1 mutant and the increase in seed sulphate content is therefore not related to a drastic perturbation of sultr4;1 vegetative growth. This was further confirmed by estimating the level of sulphate in the seed compartment (sulphate content $\times$ seed mass per plant) and per seed (sulphate content $\times 1$-seed weight), which increased by $\sim 60 \%$ in sultr4; 1 seeds compared to wild-type (see Additional file 3).

For the other anions measured, only nitrate content was found to increase in sultr4; 1 seeds but nitrate levels in the seed compartment or per seed were not significantly different compared to wild-type (see Additional file 3), suggesting sultr4;1 is particularly affected in seed sulphate

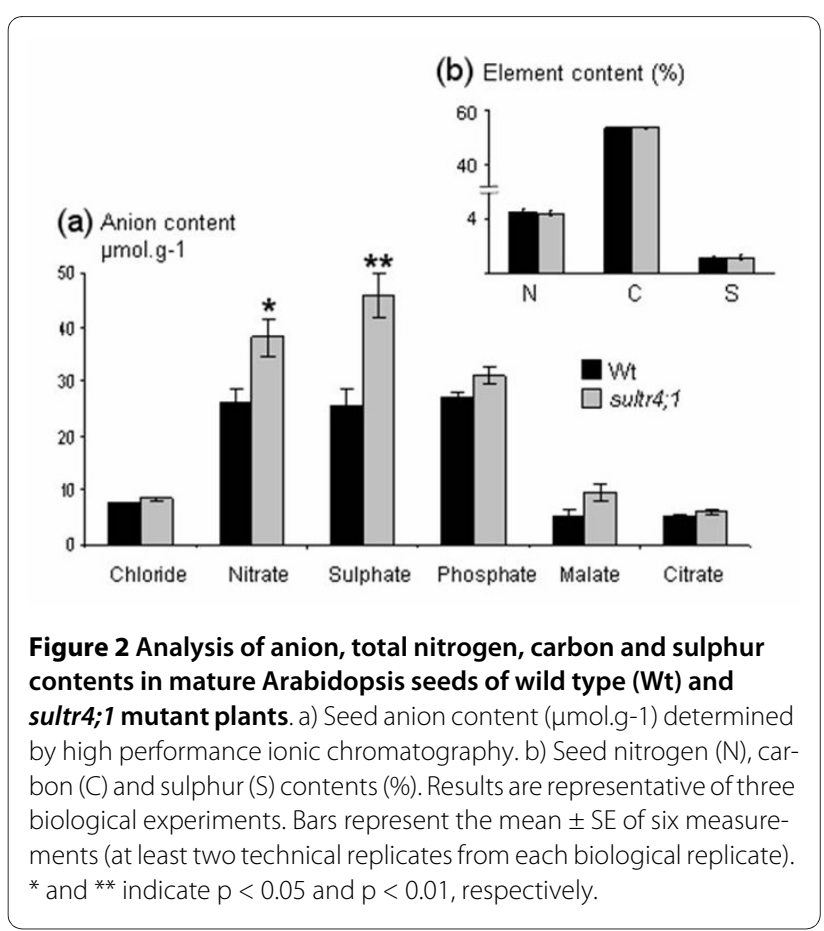




\section{(a) Leaf surface at flowering ( $\mathrm{cm} 2)$}
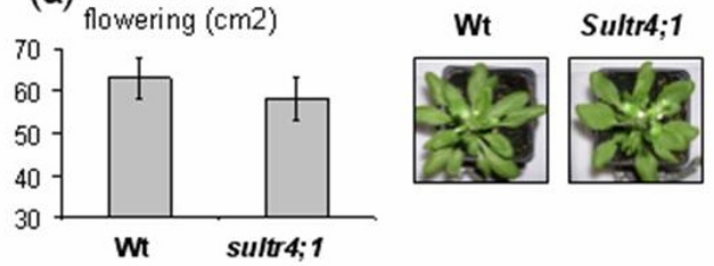

(b) Seed yield (g)

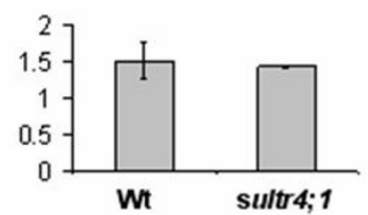

(c) 100 seed weight (mg)

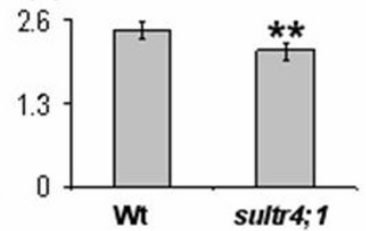

Figure 3 Projected rosette leaf surface at flowering a), seed yield b), and seed weight c) of wild-type and sultr4;1 mutant plants Each bar represents the mean \pm SE of at least three biological replicates. The data were submitted to variance analysis. ${ }^{*}$ and ${ }^{*}$ indicate $p$ $<0.05$ and $p<0.01$, respectively.

content. The significant increased pool of sulphate in mature seeds of the sultr4;1 mutant could be related to a reduced efflux of sulphate from the vacuoles during seed development, therefore no longer accessible for its assimilatory reduction.

\section{Alterations in protein quantities in sultr4;1 mature seeds}

To determine if the increased sulphate content in sultr4;1 seeds, putatively due to a reduced vacuolar efflux capability, has influenced seed composition, seed nitrogen and carbon contents were analysed along with the seed proteome complement. In mature sultr4;1 seeds, nitrogen and carbon amounts were unchanged (Figure 2b) but important proteome changes were observed as compared to wild-type. With regard to the proteome analysis, total proteins were extracted from three biological replicates and separated by 2D electrophoresis. Image analysis of Coomassie Blue gels using the Samespots software allowed the quantification of protein abundance for 273 well-resolved spots (see Additional files 4 and 5). Statistical analyses (ANOVA and Levene tests) highlighted 29 spots for which the abundance in sultr4;1 seeds varied significantly compared to wild-type (see Figure 4a and Additional file 6). It is worth noting that among these 29 spots, 28 showed a higher relative abundance level in sultr4;1 seeds, whereas only one spot (spot 239) showed a decreased accumulation.

To study the putative function of the proteins whose abundance varied or remained unchanged in sultr4;1 seeds, we annotated 152 spots detected in 2D gels by using proteome reference maps previously established for
Arabidopsis seeds [[25,26] and [27]]. The identity of 59 spots was confirmed by tryptic peptide mass fingerprinting or LC-MS/MS (see Additional file 7). Of the 29 spots varying in the sultr4;1 seed proteome, 25 were identified. The metabolic pathways modulated in mutant seeds compared to wild-type were revealed by classifying the proteins into functional categories according to the gene ontology of Bevan et al. [28] (see Additional files 5 and 6). The distribution into each functional category of proteins whose abundance varied significantly, and the modulated metabolic pathways, are shown in Figures 4 and 5 respectively. In mutant seeds, most of the spots whose abundance varied as compared to wild-type were related to metabolism (eleven spots of 17 identified), detoxification (four spots of nine identified) and energy (four spots of 13 identified).

Within the metabolism category, lipid and sterol metabolism was particularly affected in mutant seeds: among the five spots identified as proteins related to lipid and sterol metabolism, four (spots 59, 235, 202 and 130) showed an increased abundance in mutant seeds. Sugar and polysaccharide metabolism may also be modulated in mutant seeds, since several spots corresponding to enzymes involved in polysaccharide catabolism, a $\beta$-glucosidase [spots 15, 38 (Figure 4), 83 and 134] and a $\beta$ galactosidase (spot 27), increased in mutant seeds. Finally two proteins of amino acid metabolism were also overaccumulated in the sultr4;1 mutant seeds that correspond to glutamine synthase (spot 137) and methionine synthase (spot 97 in Figure 4).

Another interesting result was the over-accumulation in mutant seeds of several proteins related to stress response mechanisms. Four spots corresponding to enzymes involved in detoxification processes, a glutathione S-transferase (spot 122), an aldose reductase (spot 226), a formate dehydrogenase (spot 212), and a superoxide dismutase (spot 2, Figure 4), were over-accumulated in the Sultr4;1 mutant seeds. Moreover, spots corresponding to proteins usually up-regulated during stress response and notably oxidative stress [29-31], such as glyceraldehyde-3-phosphate dehydrogenase (spot 187) and alcohol dehydrogenase (Spot 40 in Figure 4), were increased in abundance in mutant seeds. These results prompted us to estimate the level of oxidation of the glutathione pool in seeds, which is indicative of the redox status. The amounts of reduced glutathione (GSH) and glutathione disulphide (GSSG, oxidized form) were measured in dry mature seeds freshly collected from wildtype and sultr4;1 mutant plants (see Additional file 8). The mutant seeds possessed higher GSSG levels (46\% against $42 \%$ for wild-type seeds), although the increases were not statistically significant.

In contrast to the substantial variations of proteins involved in metabolism and stress-related pathways, 


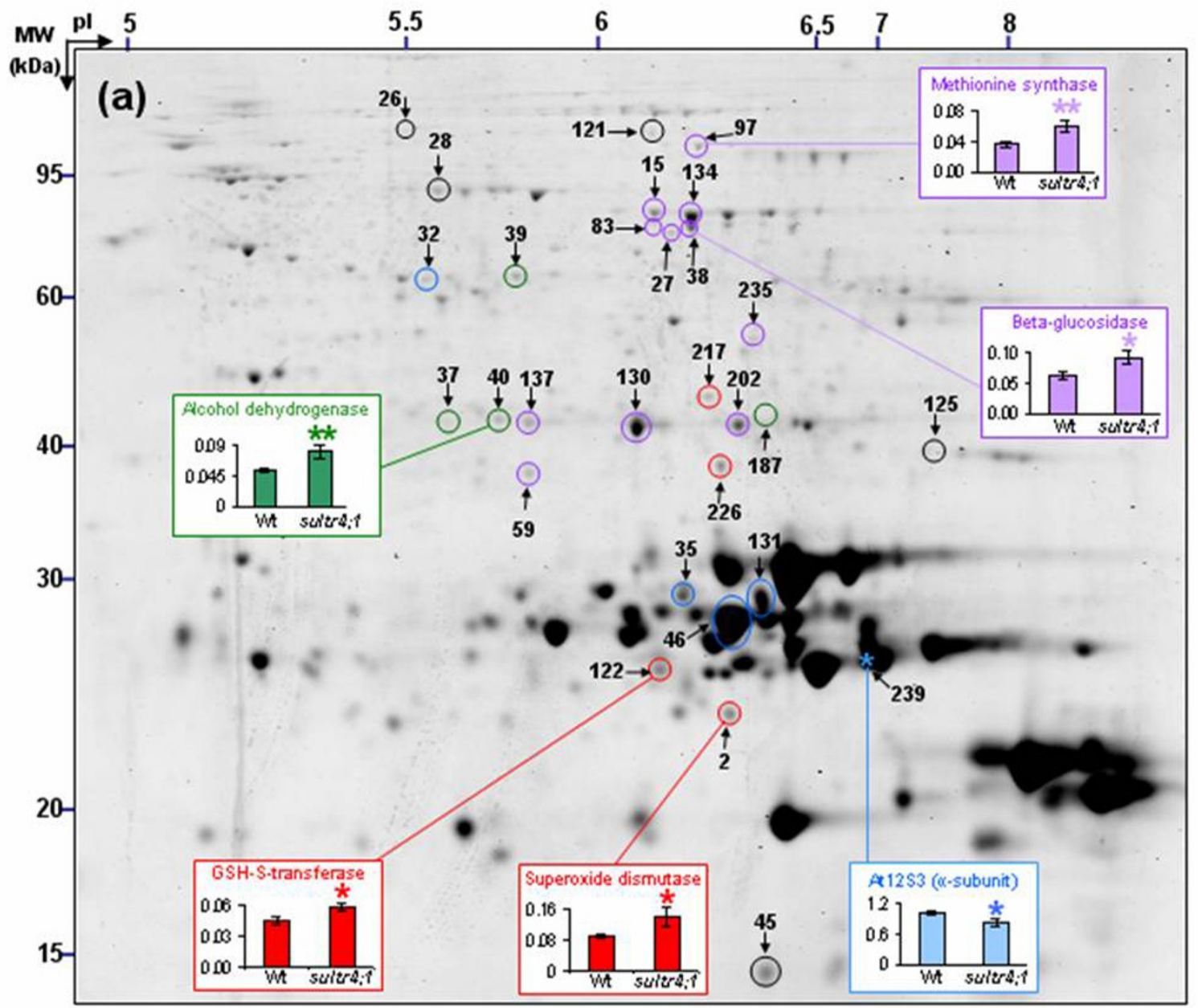

(b)

\section{Metabolism; 11 out of 17 identified}

Amino acids; $2 / 6$

Lipids and sterols; $4 / 5$

Sugars and polysaccharides; $5 / 6$

\section{Energy: 4 out of 13}

TCA; $1 / 4$

Photosynthesis; $1 / 1$

Fermentation; $1 / 1$

Glycolysis, gluconeogenesis; $1 / 7$

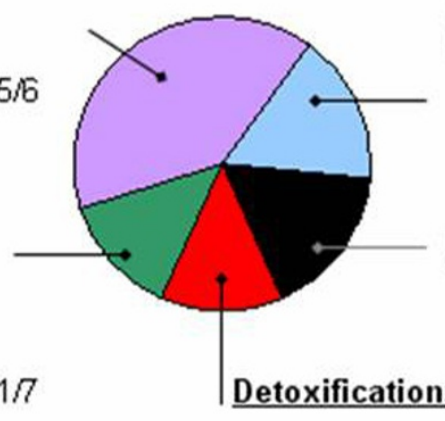

Protein destination and storage: 5 out of 76

Proteolysis; $1 / 3$

$12 S$ globulins, $4 / 57$

Unclassified; 5 out of 125

Figure 4 Proteome variations detected in mature seeds of Sultr4;1. a) A representative proteome map from mature Arabidopsis seeds is shown. Circles and stars represent proteins whose level respectively increased and decreased in sultr4; 1 mutant seeds compared to wild-type. The spots \#11, 27, 32, 40, 45, 83, 122, 134, 137, 187 and 226 were identified by using the proteome reference maps from Gallardo et al. [25,26] and Rajjou et al. [27]. The other proteins were identified by mass spectrometry in the present study (see Additional file 7 ). Colors indicate the functional category of proteins according to the ontological classification of Bevan et al. [29] (see Figure 4b, Additional files 5 and 6). Example of abundance variations for spots 2, 38, 40,97, 122 and 239 in wild-type and sultr4;1 mutant are shown. Each bar represents the mean \pm SE of at least three biological replicates. * and ** indicate $p<0.05$ and $p<0.01$ respectively (variance analysis). b) Distribution of proteins whose abundance varied significantly in each functional category. Within each class, the number of proteins whose abundance vary versus the total number of proteins identified is indicated. See Additional file 4 for a complete annotation of the proteome reference map. 


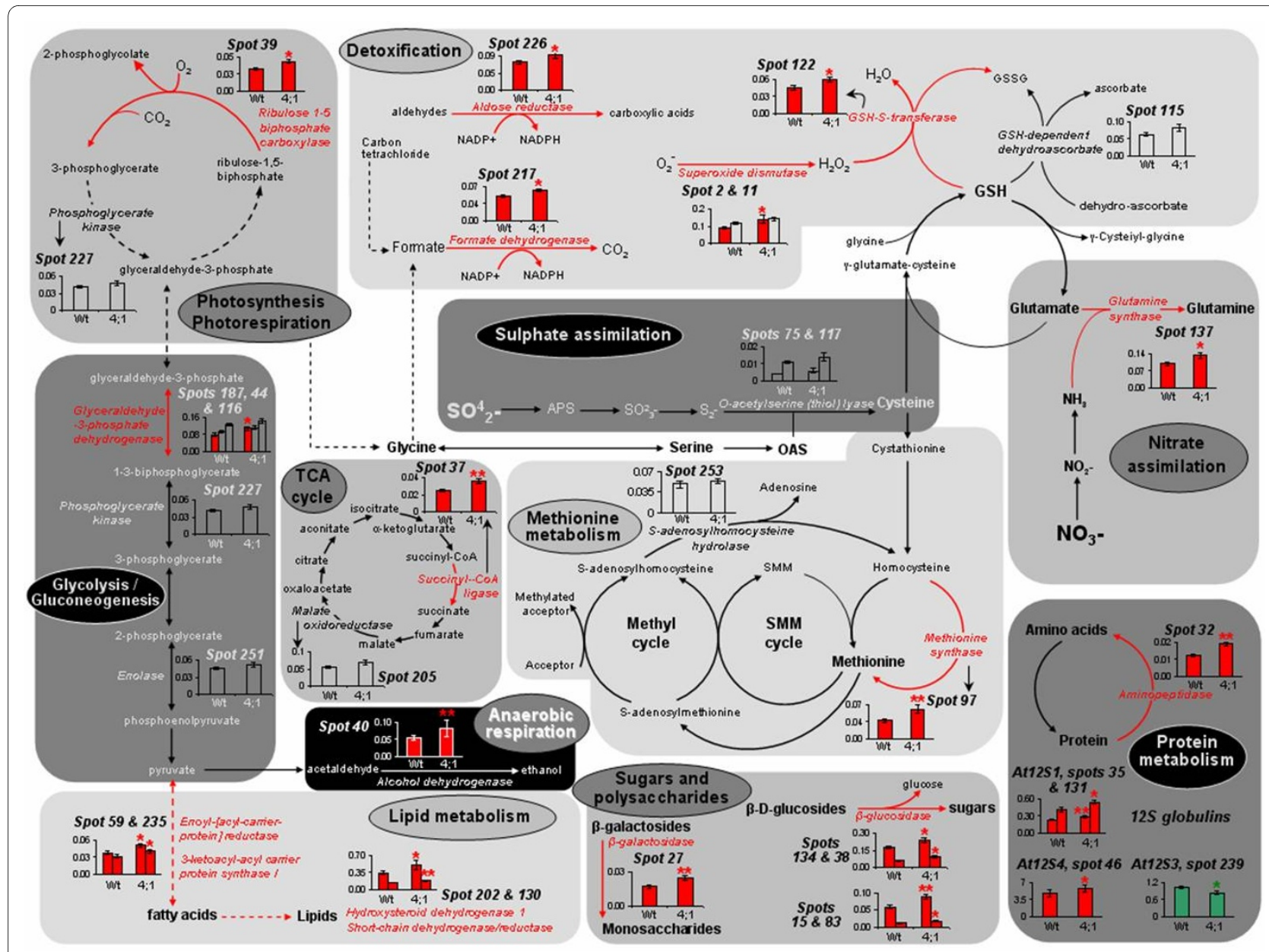

Figure 5 A summary of metabolic pathways modulated in Sultr4; 1 mutant seeds. Proteins were located in their metabolic pathways according to their annotation http://www.arabidopsis.org, ontological classification [29] and to established features of metabolism. The spots \#11, 27, 32, 40, 45, $83,122,134,137,187$ and 226 were identified by using the proteome reference maps from Gallardo et al. [25,26] and Rajjou et al. [27]. The other proteins were identified by mass spectrometry in the present study (see Additional file 7). Bars represent the means of spot level variations \pm SE in mature seeds of wild-type and sultr4; 1 mutant. Significant variations are indicated by colored red (increased levels in sultr4; 1 seeds) or green (decreased levels) bars. ${ }^{*}$ and ${ }^{* *}$ indicate $p<0.05$ and $p<0.01$ respectively (variance analysis). GSH, glutathione; GSSG, glutathione disulphide, OAS, O-acetylserine; SMM, S-methylmethionine; TCA, tricarboxylic acid cycle.

there were few changes in storage protein amounts. Of the 57 spots annotated as $12 \mathrm{~S}$ globulin isoforms, which are the most abundant proteins found in Arabidopsis seeds (i.e. they represent about $80 \%$ of total seed protein content), only four varied in abundance between wildtype and mutant seeds. Of these variable spots, three (spots 35 and 131, isoform At12S1 and spot 46, isoform At12S4) and one (spot 239, isoform At12S3, Figure 4) showed respectively an increased and a decreased accumulation in mutant seeds. These variations had no influence on seed protein content since values obtained by the Bradford assay were similar for sultr4;1 and wild-type seeds.

\section{Discussion}

In Arabidopsis, the sulphate transporter group 4 is composed of two members (SULTR4;1 and SULTR4;2), local- ized in the vacuolar membrane and reported to be expressed in roots, where a role was proposed in the efflux of sulphate from the vacuole [21]. In the present study, we observed that during the reproductive growth phase, Sultr4; 1 was preferentially expressed in developing Arabidopsis seeds at the transition between embryogenesis and seed filling and presented a relative transcript abundance much higher than Sultr4;2, which was expressed at similar levels throughout seed development (see Figure 1 and Additional file 1). These data, along with previous data reporting that SULTR4;1 plays a major role and SULTR4; 2 only a small contribution in remobilising the sulphate reserves [21], prompted us to study the role of SULTR4; 1 in determining seed composition. We found a remarkably high level of sulphate constrasting with an unchanged sulphur content in mature seeds of a sultr4;1 T-DNA mutant (Figure 2), which for the first 
time implies a function for this transporter in developing seeds. The unchanged seed sulphur content indicates that the increased sulphate level is not related to an enhanced sulphur supply to the developing seed, but rather to a reduction of sulphate utilization/assimilation within the seed. Despite the unchanged sulphur content in mature seeds, we cannot exclude that the composition of sulphur or the amount of sulphate and other sulphur metabolites transported to developing seeds could be different between the wild-type and the sultr4;1 mutant. However, as no significant difference in seed yield, leaf surface or onset of flowering were observed, the increased sulphate/ sulphur ratio in sultr4;1 seeds appears not to be related to a drastic perturbation of sultr4;1 vegetative growth. The increased sulphate/sulphur ratio in sultr4;1 seeds is possibly the consequence of a reduced remobilization (i.e. assimilation) of the vacuolar sulphate pool within the developing seed. The vacuolar localisation of the transporter in seeds has not yet been proven. We therefore cannot exclude that the protein could be localised in different compartments in seeds. However, the increased sulphate/sulphur ratio in mutant mature seeds is consistent with previous data showing that, in roots of sultr4;1 mutants, sulphate is retained as a consequence of defects in sulphate efflux from the vacuole [21]. It should also be noted, that other genes encoding sulphate transporters are expressed in developing seeds [22]. In particular, the Sultr3;4 gene encoding a putative plasma-membrane sulphate transporter is strongly expressed during early seed filling at similar stages to those of Sultr4;1. Interestingly, the seed proteome profile of the sultr4;1 mutant differs from that of a sultr3;4 mutant (unpublished data), indicating that SULTR4;1 and SULTR3;4 may have distinct roles/subcellular localization during seed filling.

Overall nitrogen and protein levels were unaltered in sultr4; 1 seeds, but a dissection of the sultr4;1 seed proteome revealed that $\sim 10 \%$ of the minor protein spots detected in $2 \mathrm{D}$ gels varied in abundance (see Additional files 5 and 6), thus reflecting metabolic modifications (Figure 5). In particular, several proteins with roles in the oxidative stress response were up-accumulated. An oxidative stress response has frequently been observed during sulphate deprivation [32,33], notably in sulphurdeficient seeds [34]. In the present study, most of the proteins with roles in the oxidative stress response are involved in detoxification mechanisms (Figure 5). Among them were a scavenger of free oxygen radicals (superoxide dismutase, spot 2 in Figure 4), and the glutathione $S$ transferase isoform 6 (spot 122 in Figure 4) that may play a protective role against oxidative damage due to hydrogen peroxide [35]. This may represent an adaptive response to oxidative stress in sultr4;1 seeds as these enzymes detoxify some of the toxic compounds, such as reactive oxygen species (ROS), produced by oxidative stress.

At low levels, ROS participate in cellular signaling. In Arabidopsis seeds, abundant proteins were identified that act as scavengers of ROS generated during seed development, thereby counteracting their deleterious effects [36]. However, if ROS accumulate to harmful levels, seeds lose their ability to control ROS and cannot restart their metabolism [37], probably because ROS cause irreversible oxidative damage to lipids, proteins, and DNA. We have observed that Sultr4; 1 seeds lose their viability during storage much more rapidly than wild-type seeds. Indeed, seeds collected from homozygous Sultr4;1 plants did not germinate after two years of storage at room temperature, while almost all seeds collected at the same time from wild-type plants germinated. A tetrazolium test confimed the loss of viability of the Sultr4;1 mutant seeds (see Additional file 9), which could be linked to their increased sensitivity to oxidative stress during storage, when ROS are known to be continuously produced [38]. However, the up-regulation of enzymes involved in ROS removal that we see in sultr4;1 seeds probably reflects seed developmental events and not changes during sample storage, as the seeds subjected to proteomics were frozen in liquid nitrogen immediately after harvest.

In summary, our data suggest sulphate remobilization from the vacuole to the other cell compartments is important for the seed's defence against abiotic oxidative stress during seed development and storage. This could also apply to other tissues, since in Arabidopsis roots and shoots, cadmium stress induces an up-regulation of Sultr4; 1 gene expression concomitantly with an oxidative stress response [39]. Also, in Brassica juncea seedlings, Sultr4; 1 gene expression was up-regulated in response to arsenic-induced stress $[40,41]$, which leads to the generation of ROS through the conversion of arsenate to arsenite [42].

Besides proteins related to the oxidative stress response, an up-accumulation of proteins involved in the biosynthesis of fatty acids and lipids was revealed. They correspond to enoyl- [acyl-carrier-protein] reductase (spot 59 in Figure 4), two isoforms of hydroxysteroid dehydrogenase 1 (HSD1, spots 130 and 202), and ketoacyl carrier protein synthase I (spot 235). An up-regulation of a ketoacyl carrier protein synthase was also observed in developing Arabidopsis seeds under sulphur-starved conditions [34]. It is well known that under stress conditions, toxic oxygen derivatives are produced that inactivate enzymes and damage important cellular components, such as membranes via lipid peroxidation and fatty-acid de-esterification. In this context, the up-regulation of enzymes involved in fatty acid and lipid biosynthesis may represent a mechanism to repair stress-induced mem- 
brane damage. In support of this, $\mathrm{Li}$ et al. [43] showed that transgenic Arabidopsis lines overexpressing HSD1 have an increased tolerance to salt stress.

Interestingly, an up-regulation in proteins of the energy and carbon metabolism was observed in sultr4;1 seeds. These are involved in glycolysis (glyceraldehyde-3-phosphate dehydrogenase, spot 187), photosynthesis or photorespiration (ribulose 1-5 biphosphate carboxylase large chain, spot 39), and anaerobic fermentation (alcohol dehydrogenase, spot 40 in Figure 4). Since an up-accumulation of enzymes involved in fatty acid and lipid biosynthesis was also observed in sultr4;1 seeds, it is possible that energy production and glycolysis were enhanced in sultr4;1 seeds to provide carbon skeletons for the synthesis of fatty acid precursors in these seeds [44]. Furthermore, members of the glycosyl hydrolases that specifically release sugar from oligosaccharides $[\beta$-glucosidase, spots 15, 38 (Figure 4), 83, 134; and $\beta$-galactosidase, spot 27 (Figure 5)] were up-accumulated in sultr4;1, probably as a way to sustain glycolysis and fatty acid biosynthesis.

This study demonstrated that the accumulation of storage proteins occurs in sultr4; 1 mutant seeds (see Additional files 5). In 2D-gels, these proteins are located in the 20 to $30 \mathrm{kDa}$ range (see Figure 4a and Additional files 4 and 5). Only a few storage proteins differ in abundance from wild-type seeds and these correspond to globulin $12 \mathrm{~S}$ isoforms (Figure 5 ). The only protein whose level decreased was the At12S3 isoform (spot 239 in Figure 4a) and the three proteins whose level increased were At12S1 (spots 35 and 131) and At12S4 (spot 46). Interestingly, the isoforms whose level increased have a relatively poor sulphur amino acid content (2.4 and 2.8\%, respectively) compared to At12S3 (4.3\% of total amino acid residues) whose level decreased. A similar increase in sulphur-poor seed proteins was observed during sulphur deprivation $[34,45-47]$. This indicates that, in sulphur-sufficient conditions, sulphate exported from the vacuole via SULTR4;1 participates but is not limiting for storage protein synthesis. A possibility to be considered is that SULTR4;2 could also participate to vacuolar sulphate release for storage protein synthesis. However, expression patterns of the gene and data from the literature suggest SULTR4;2 may have only a supplementary role in sulphate export from the vacuole [21].

Interestingly, an increased accumulation of a methionine synthase (spot 97, Figure 4) was observed in sultr4;1 seeds. It is also worth noting that under sulphatedeprived conditions, despite the almost complete depletion of cysteine, the plant is able to keep methionine levels constant $[32,48,49]$. This demonstrates the plant's capacity to regenerate methionine through alternative pathways under sulphate-deficient conditions and upon cysteine restriction. Methionine can be regenerated through methylation of homocysteine produced by transmethylation via a reaction catalyzed by S-adenosylhomocysteine hydrolase (Figure 5). Moreover, the use of the 4carbon moiety of $S$-adenosylmethionine for the synthesis of polyamines and ethylene also is accompanied by recycling of the methylthio moiety and regeneration of methionine [50]. Interestingly, the protein spot identified in the present study corresponds to a cytosolic isoform involved in the regeneration of methionine from homocysteine produced in the course of the activated methyl cycle [51]. In sultr4; 1 mutant seeds, the up-regulation of methionine synthesis could be a way to sustain seed protein synthesis. Moreover, maintaining the synthesis of proteins rich in methionine may be particularly important in stress conditions, since protein-endogenous methionine reacts with ROS, as a scavenger, to form sulphoxide (MetSO) without loss of activity of the corresponding protein $[52,53]$.

\section{Conclusions}

This study revealed a role for SULTR4; 1 in determining sulphate content of mature Arabidopsis seeds, possibly because it controls the efflux of sulphate from the vacuoles for metabolism in other cell compartments [21]. Specific seed metabolic features were also revealed through a fine dissection of the seed proteome of a sultr4;1 mutant (Figures 4 and 5). In particular, an up-regulation of proteins involved in the oxidative stress response was revealed that suggests a function of SULTR4; 1 in maintaining redox homeostasis during seed development. The maintenance of redox homeostasis is of crucial importance in plant tissues, and even more in seeds that have the ability to tolerate dehydration in the course of their development. This remarkable ability allows the orthodox seed, i.e., seed that can be stored in a state of low moisture content [54], to survive for several years in a desiccated state with metabolic activities at a standstill, until the environmental conditions become optimal for its germination. As seed desiccation enhances ROS formation, mechanisms that protect from oxidative stress are therefore crucial for maintaining cellular integrity and homeostasis [55]. Glutathione, which is a sulphur-derived product, is a major plant antioxidant. During desiccation, it is converted into the oxidized form glutathione disulphide (GSSG) and the balance between these two compounds is crucial for homeostasis and seed survival. Indeed, the GSSG versus GSH ratio can be applied to assess seed viability, since an increased ratio was typically correlated with viability loss in Pisum sativum seeds [54]. In the present study, we observed that mutant seeds, freshly collected at the dry mature stage, possessed higher GSSG levels, although the increases were not statistically significant (see Additional file 8). It is worth noting that generally, the level of GSSG is much higher in 
mature seeds than in other plant parts. For example, only $10 \%$ of total glutathione is oxidized in Arabidopsis seedlings [56,57]. This indicates that the glutathione pool is relatively highly oxidized in mature Arabidopsis seeds compared to other plant organs. Despite the absence of significant changes in GSH and GSSG levels between wild-type and mutant seeds, we cannot exclude a localized disturbance of the redox balance in particular tissue or subcellular compartments of sultr4;1 mutant seeds. Indeed, as reported by Meyer et al. [58], measurements of GSSG/GSH ratios in plant tissues are prone to artefacts since they do not take into consideration the subcellular compartmentalization. Also, partial oxidation of glutathione during extraction is difficult to avoid and a slight increase in GSSG concentration, whilst barely detectable, would suffice to shift the glutathione redox potential to significantly less reducing values [59]. For these reasons, and because GSSG/GSH ratio in mature seeds is not representative of the events occurring at specific stages of seed development or during storage, future studies will be necessary to evaluate the redox status in different cell types throughout seed development and storage. Very little is known about the exact role of sulphate released from the seed vacuoles in the course of seed development in maintaining cellular homeostasis during seed development. Although further studies will be necessary, this paper is the first contribution on this topic.

\section{Methods}

\section{Plant materials and growth conditions}

We studied Arabidopsis T-DNA insertion lines (Columbia ecotype, Col-0) from the Nottingham Arabidopsis Stock Center (Nottingham University, UK) for the gene 4;1 (AT5G13550). The T-DNA line has the following accession number: SALK-120920. Further information about mutant accession and T-DNA localization can be found at http://arabidopsis.info and http://atidb.org. The T-DNA insertion line used in this study was not backcrossed and a single allele was used, but conscious of the presence of other insertions in the genome and of the limitations of using only one allele, we have taken care to compare several mutant plants to several wild-type plants derived from plants segregating the mutant allele, to minimize the possible effect of insertions elsewhere in the genome. The plants were grown under sulphur-sufficient conditions (peat-perlite mixture) in a greenhouse with supplemental light to $16 \mathrm{~h} /$ day, and fertilized three times a week by subirrigation (N-P-K: 20-20-20). For genotyping, DNA was extracted from a leaf disk by using the CTAB method from Doyle and Doyle [60]. A PCR screen was performed by using specific primers for each gene binding upstream and downstream of the predicted TDNA insertion as well as one primer binding in the left border region of the corresponding T-DNA. The follow- ing primers were used: Lba2-for(5'-GAACAACACTCAACCCTATCTC-3') for the T-DNA, and 4;1-for(5'GCA TTCGTTATCCACGAGTCTG-3') and 4;1-rev(5'CTCTGTACGTATTGTAGACA CAC-3') for the genespecific primers.

\section{Phenotypic characters}

Rosette leaf area and seed yield were measured from at least three individual plants. Leaf area was quantified from the rosette scan at flowering using the Visilog 5.4 software (Noesis, Les Ulis, France). The onset of flowering was scored and expressed in ${ }^{\circ} \mathrm{C} /$ day. Seed weight was determined from three seed samples of $10 \mathrm{mg}$ (around 400 seeds) collected on three individual plants. All data were submitted to statistical analyses (variance analysis) using the Statistica 7.0 software (Maisons-Alfort, France). Only differences with $P$ values $<0.05$ were considered significant.

\section{Tetrazolium test}

Seed viability was estimated by using the tetrazolium test, which differentiates viable from dead tissues of seed embryos on the basis of dehydrogenase activity (respiration enzymes) that reduces tetrazolium salt to formazan in viable tissues. The mutant and wild-type seeds collected at the same time and stored under the same conditions for 25 months were imbibed 24 hours in water. Twenty five embryos from wild-type and mutant seeds were isolated and placed for one hour in a $0.25 \%$ tetrazolium salt solution (2,3,5-triphenyltetrazolium chloride).

\section{RNA extraction and quantitative real-time PCR}

Silique and seed samples at three stages of development (pods at 7 and 10 days after flowering, and mature seeds) and tissue samples (flowers, roots, leaves, stems) were collected on two independent batches of plants. Frozen tissues were ground in liquid nitrogen and total RNA was extracted using the method described by Chang et al. [61]. RNAs $(10 \mu \mathrm{g})$ were incubated in presence of 10 units of RNAse-free RQ1 DNAse (Promega, Madison, USA). Non reverse-transcribed RNA samples were checked for absence of contaminating genomic DNA by PCR using primers for the constitutively expressed elongation factor alpha-chain gene (At5g60390). DNA-free RNA was converted into first-strand cDNA. Samples were reversetranscribed using the iScript cDNA synthesis Kit (BioRad, Hercules, USA). The quantitative RT-PCR was performed using the real-time SYBR Green method on a BioRad iQ5 thermal cycler, using iQ SYBR Green Supermix (BioRad) and the following specific primers: 4;1for(5'-CACTTGACAATAGCAAGATCAGG-3'), 4;1-rev (5'-CTCTGTACGT ATTGTAGACACAC-3'), 4;2-for(5'CTAGCAAGAGCAGGCATTGTGGA-3') and 4;2-rev (5'-CTTGGACTGCGTCATGTACTCTC-3'). To establish the presence of a single PCR product and the absence 
of primer-dimers, melting curve analysis (i.e. heat dissociation of oligonucleotides) was applied immediately after PCR by heating PCR products from $59^{\circ} \mathrm{C}$ to $96^{\circ} \mathrm{C}$. Normalization for cDNA quantity was performed for each template with an Elongation factor gene (At5g60390) as control gene using the relative standard curve method (delta CT) according to the Biorad instructions. The expression stability of the control gene in the different test samples was verified by comparison with two other constitutively expressed genes encoding an ubiquitin (At4g27960) and a protein phosphatase (At1g13320) (data not shown). The following control primers were used: for(5'-GATTGCCACACCTCTCACATTGCAG-3') and $\operatorname{rev}\left(5^{\prime}\right.$-GCTCCTTCTCAATCTCCTT ACCAG-3') for the elongation factor gene, for(5'-CCAAGGTGCTGCTATCGATCTGT-3') and rev (5'-AGGTCCGAGCAGTG GACTCG-3') for the ubiquitin gene and for(5'ATCGCTTCTCGCTCCAGTAATG-3') and rev(5'-GACTATCGGAATGAGAGATTGC-3') for the protein phosphate gene. This method was also applied to assess transcript level changes in mature seed of sultr4;1 mutant compared to wild-type. A 94-99\% decrease was observed in sultr4; 1 seeds.

Determination of anion and N C S contents in mature seeds Mature seeds harvested from three individual plants were ground $(50 \mathrm{mg}$ ) in liquid nitrogen. Anions were extracted in Milli-Q water heated at $70^{\circ} \mathrm{C}$ for $20 \mathrm{~min}$. The seed extract was centrifugated at least 3 times at 20,000 $\mathrm{g}$ for $10 \mathrm{~min}$ at $4^{\circ} \mathrm{C}$. Anion content of the final clear supernatant was determined by high performance ionic chromatography (LC20 Dionex) using a IonPaq AS11 column and a sodium hydroxide linear gradient ( 1 to $22 \mathrm{mM}$ ), as described [17]. Contents of total nitrogen, carbon and sulphur in the dried powder of seed samples were measured were measured using an elemental analyzer (Vario EL; Elemental analyser system). All data were submitted to statistical analyses (variance analysis) using the Statistica 7.0 software (Maisons-Alfort, France). Only differences with $P$ values $<0.05$ were considered significant.

\section{Glutathione content and redox state}

$20 \mathrm{mg}$ of seeds were used for isolation of total or oxidized thiols as described in Fey et al. [57]. Derivatization of thiols with monobromobimane (Calbiochem) and separation of thiol derivates were performed according to Wirtz et al. [62] using the same HPLC-system. The Empower ${ }^{\text {тM }}$ software (Waters) was used for data acquisition and processing.

\section{Total protein extraction and $2 \mathrm{D}$ electrophoresis}

The seed samples (dry mature stage) subjected to proteomics were immediately frozen in liquid nitrogen after harvest to avoid changes in protein abundance that can be induced by storage. Total proteins were extracted as described by Gallardo et al., [63], from $20 \mathrm{mg}$ of mature seeds collected on four individual plants. Protein concentration was measured according to Bradford [64]. Eight gels (four biological replicates and two technical replicates from each biological replicates) were performed for each wild-type and mutant lines. A constant volume (57 $\mu \mathrm{l})$ of the protein extracts (around $200 \mu \mathrm{g}$ of proteins) was used for isoelectrofocusing, that corresponded to a constant seed weight $(2 \mathrm{mg})$. Proteins were separated in duplicates using gel strips forming an immobilized nonlinear $\mathrm{pH} 3$ to 10 gradient (Immobiline DryStrip, $24 \mathrm{~cm}$; GE Healthcare/Amersham Biosciences). Strips were rehydrated in the IPGphor system (GE Healthcare/Amersham Biosciences) for $7 \mathrm{~h}$ at $20^{\circ} \mathrm{C}$ with the thiourea/urea lysis buffer containing $2 \%(\mathrm{v} / \mathrm{v})$ Triton X-100, $20 \mathrm{mM}$ DTT and the protein extracts. IEF was performed at $20^{\circ} \mathrm{C}$ in the IPGphor system for $7 \mathrm{~h}$ at $50 \mathrm{~V}, 1 \mathrm{~h}$ at $300 \mathrm{~V}, 2 \mathrm{~h}$ at $3.5 \mathrm{kV}$ and $7 \mathrm{~h}$ at $8 \mathrm{kV}$. Prior to the second dimension, each gel strip was incubated at room temperature for $2 \times$ $15 \mathrm{~min}$ in $2 \times 15 \mathrm{ml}$ equilibration buffer as previously described [26]. Proteins were separated in vertical polyacrylamide gels according to [26].

\section{Protein staining and quantification}

Gels were stained with Coomassie Brilliant Blue G-250 (Bio-Rad, Hercules, CA, USA) according to Mathesius et al. [65] Image acquisition was done using the Odyssey Infrared Imaging System (LI-COR Biosciences, Lincoln, $\mathrm{NE})$ at $700 \mathrm{~nm}$ with a resolution of $169 \mu \mathrm{m}$. Image analyses and spot volume quantification were carried out with the Progenesis SameSpots version 2.0 software (Nonlinear Dynamics, Newcastle upon Tyne, UK) according to the instruction manual. For each gel, normalized spot volumes were calculated as the ratio of each spot volume to the total spot volume of the gel (arbitrary unit). Eight gels (four biological replicates and two technical replicates from each biological replicates) were analysed for each wild-type and mutant lines. Molecular masses $(\mathrm{Mr}$ ) and isoelectric points $(\mathrm{p} I)$ were calculated according to the migration of standard proteins (Bio-Rad, Bio-Rad, Hercules, USA). All data were submitted to statistical analyses (variance analysis and Levene's test) using the Statistica 7.0 software (Maisons-Alfort, France). Only differences with $\mathrm{p}$-values $<0.05$ were considered significant.

\section{Protein identification}

Spots were annotated using proteome reference maps previously established for Arabidopsis mature seeds ([2527], http://www.seed-proteome.com). In the present work, we confirmed identification of 53 spots by nanoLC-MS/MS (Q-TOF-Ultima Global equipped with a nano-ESI source coupled with a Cap LC nanoHPLC, Waters Micromass, Waters, Saint Quentin en Yvelines, France) as described by Gallardo et al. [66]. Detailed 
information about protein digestion, mass spectrometry data acquisition are in Additional file 7. Peak lists of precursor and fragment ions were matched to proteins in the NCBI non redundant database (March 2008, 7,387,702 sequences; 2,551,671,261 residues, taxonomy of Arabidopsis) using the MASCOT version 2.2 program (Matrix Science, London). The MASCOT search parameters are described in Additional file 7. Only matches with individual ion scores above 20 were considered.

\section{Additional material}

Additional file 1 Comparison of the QRT-PCR data obtained in the present study for the Arabidopsis genes belonging to the group 4 of sulphate transporters with the corresponding data from a publicly available expression atlas [22]. A drawing was made from a photo of the Arabidopsis plant and, for each gene, gene expression in roots, rosette and cauline leaves, entire flower, stem, and seeds, from the publicly available expression atlas of Arabidopsis was mapped as colors. The qRT-PCR expression data are indicated by colored squares. These expression data were normalized to the highest expression value set to 1 . A color scale represents variations in transcript abundance for each gene, in which red represents the highest expression and white the lowest expression. Missing values are in grey. Microarray data showing Sultr4; 1 expression in roots of young seedlings under sulfur-starvation conditions, versus normal conditions (AthXpressionist@CSB.DB, http://csbdb.mpimp-golm.mpg.de/csbdb/dbxp/ath/ ath xpmgq.html) were also included.

Additional file 2 Structure of the Sultr4; 1 gene, T-DNA insertion site and trancript level (qRT-PCR) in wild-type and mutant lines. a) Structure of Sultr4; 1 gene is shown with the insertion site of the T-DNA (SALK120920). Exons are indicated by white boxes, untranslated regions by dark boxes and T-DNA insertion by a dashed box. b) The relative mRNA quantity was estimated by qRT-PCR in mature seeds of wild-type (Wt) and sultr4; 1 mutant plants. Bars represent the mean \pm SE of three biological replicates.

Additional file 3 Estimation of anion levels in the seed compartment (a) and per 100 seed (b) for wild type (Wt) and the sultr4; 1 mutant. a) Anion levels correspond to seed anion content * seed mass per plant. b) Anion levels correspond to seed anion content * 100-seed weight. Seed anion content was determined by high performance ionic chromatography. Results are representative of three biological experiments. Bars represent the mean \pm SE of six measurements (at least two technical replicates from each biological replicate). ${ }^{*}$ and ${ }^{* *}$ indicate $p<0.05$ and $p<0.01$ respectively (variance analysis).

Additional file 4 Proteome map of mature Arabidopsis seeds Col-0, wild-type. Total soluble proteins were electrofocused in a non-linear $\mathrm{pH}$ gradient from 3 to 10, then separated by SDS-PAGE (10\%) (see Additional files 5 and 6 ).

Additional file 5 Proteomics datasets from mature seeds in wild-type and mutant lines. This table includes: MW and pl of the 273 detected proteins, their accumulation ratios (mutants versus wild-type), the ANOVA and Levene $P$ values, their annotation and ontological classification [29].

Additional file 6 Detailed information concerning proteins whose abundances vary significantly between mutant and wild-type mature seeds. This table includes: MW and pl of the 29 proteins whose abundance vary significantly, their annotation, ontological classification [29], and their accumulation level in wild-type and mutant seeds. Bars represent the mean \pm SE of six measurements (at least two technical replicates from each biological replicate). ANOVA and significant differences are labelled: ${ }^{*}{ }^{* *}$ and *** indicate $p<0.05, p<0.01$ and $p<0.001$ respectively.

Additional file 7 Detailed information about LC-MS/MS protein identification. This table includes detailed information about protein digestion, mass spectrometry, data acquisition, MASCOT search parameters, peptide sequences and identification scores.

Additional file 8 Total glutathione, glutathione disulphide (GSSG), reduced glutathione (GSH) in mature seeds of wild type and sultr4; 1 mutant lines.
Additional file 9 Viability estimation of dry mature seeds freshly collected from the sultr4;1 mutant and wild type plants by using the tetrazolium test. Pictures are representative of twenty five embryos from wild-type and mutant seeds placed for one hour in a tetrazolium salt solution (2,3,5-triphenyltetrazolium chloride). Red coloration allows visualizing the living part of the embryo. All embryos isolated from wild-type seeds were stained red, thus attesting to their viability. In contrast, all embryos from mutant seeds were unstained, indicating a loss of viability.

\section{Competing interests}

The authors declare that they have no competing interests.

\section{Authors' contributions}

$\mathrm{HZ}$ participated in experimental design, conducted the bulk of the experimental work, performed the GRT-PCR experiment, 2D-electrophoresis analyses, phenotypic T-DNA mutant characterisation and statistical analyses and drafted the manuscript. JCD performed the HPIC analyses and was involved in revising the manuscript critically. MW and RH performed CNS and GSSG/GSH analyses and were involved in revising the manuscript critically. RT participated in designing and surpervising the study and helped to draft the manuscript. KG conceived, designed and supervised the study and participated in drafting the manuscript. All authors have read and approved the final manuscript.

\section{Acknowledgements}

This work was supported by a Ph.D. fellowship jointly funded by INRA (Plant Breeding and Genetics Department) and the Burgundy Regional Council. We acknowledge the Nottingham Arabidopsis Stock Center for providing us with the Arabidopsis T-DNA insertion lines. We thank Anne-Lise Santoni, Grégoire Aubert, Myriam Sanchez, Delphine Aimé, Catherine Conreux and Jean Potier (Legume Ecophysiology and Genetics Research Unit, INRA-Center at Dijon) for their very valuable technical support. We thank Sylvain Jeandroz and Marion Corneillat (AgroSup Dijon) for helpful advice during manuscript revision as regards to GSH measurements. We thank Hoai-Nam Truong and Ruth PérezVergas (Legume Ecophysiology and Genetics Research Unit, INRA-Center at Dijon) for critical reading of the manuscript and helpful discussions.

\section{Author Details}

1UMR102 Genetics and Ecophysiology of Grain legumes, INRA, F-21000 Dijon, France, 2 UMR5004 Biochemistry and Plant Molecular Physiology, Montpellier SupAgro/CNRS/INRA/Université Montpellierll, F-34060 Montpellier, France, ${ }^{3}$ Heidelberg Institute of Plant Sciences, University of Heidelberg, D-69120 Heidelberg, Germany and 4Proteomic Analysis Center of Marseille, IFR Jean Roche, F-13916 Marseille Cedex 20, France

Received: 4 September 2009 Accepted: 28 April 2010 Published: 28 April 2010

\section{References}

1. McGrath SP, Zhao F, Crosland AR, Salmon SE: Sulphur status in British wheat grain and its relationship with quality parameters. Asp Appl Biol 1993, 36:317-326.

2. Schnug E: Sulphur nutritional status of European crops and consequences for agriculture. Sulphur Agric 1991, 15:7-12.

3. Zhao F, McGrath SP: Assessing the risk of sulphur deficiency in cereals. J Sci Food Agric 1993, 63:119.

4. Buchner P, Takahashi H, Hawkesford MJ: Plant sulphate transporters: coordination of uptake, intracellular and long-distance transport. J Exp Bot 2004, 55:1765-73.

5. Kaiser G, Martinoia E, Schroppelmeier G, Heber U: Active-transport of sulfate into the vacuole of plant cells provides halotolerance and can detoxify SO2. J Plant Physiol 1989, 133:756-763.

6. Martinoia E, Massonneau A, Frangne N: Transport processes of solutes across the vacuolar membrane of higher plants. Plant Cell Physiol 2000, 41:1175-1186

7. Martinoia E, Maeshima M, Neuhaus HE: Vacuolar transporters and their essential role in plant metabolism. J Exp Bot 2007, 58:83-102.

8. Tabe L, Droux M: Sulfur assimilation in developing lupin cotyledons could contribute significantly to the accumulation of organic sulfur reserves in the seed. Plant Physiol 2001, 126:176-187. 
9. Rouached H, Berthomieu P, El Kassis E, Cathala N, Catherinot V, Labesse G, Davidian JC, Fourcroy P: Structural and Functional Analysis of the Cterminal STAS (Sulfate Transporter and Anti-sigma Antagonist) Domain of the Arabidopsis thaliana Sulfate Transporter SULTR1.2. J Biol Chem 2005, 280:15976-15983.

10. Tomatsu H, Takano J, Takahashi H, Watanabe-Takahashi A, Shibagaki N, Fujiwara T: An Arabidopsis thaliana high-affinity molybdate transporter required for efficient uptake of molybdate from soil. Proc Natl Acad Sci USA 2007, 104:18807-12

11. Hawkesford MJ: Transporter gene families in plants: the sulphate transporter gene family: redundancy or specialization? Physiol Plant 2003, 117:115-163.

12. Smith FW, Ealing PM, Hawkesford MJ, Clarkson T: Plant members of a family of sulfate transporters reveal functional subtypes. Proc Natl Acad Sci USA 1995, 92:9373-9377.

13. Smith FW, Hawkesford MJ, Ealing PM, Clarkson DT, Vanden Berg PJ, Belcher AR, Warrilow AG: Regulation of expression of a CDNA from barley roots encoding a high affinity sulphate transporter. Plant $J 1997$, 12:875-84.

14. Takahashi H, Watanabe-Takahashi A, Smith FW, Blake-Kalff M, Hawkesford MJ, Saito K: The roles of three functional sulphate transporters involved in uptake and translocation of sulphate in Arabidopsis thaliana. The Plant J 2000, 23:171-182.

15. Shibagaki N, Rose A, McDermott JP, Fujiwara T, Hayashi H, Yoneyama T, Davies JP: Selenate-resistant mutants of Arabidopsis thaliana identify Sultr1;2, a sulfate transporter required for efficient transport of sulfate into roots. Plant J 2002, 29:475-486.

16. Yoshimoto N, Takahashi H, Smith FW, Yamaya T, Saito K: Two distinct high-affinity sulfate transporters with different inducibilities mediate uptake of sulfate in Arabidopsis roots. Plant J 2002, 29:465-473.

17. El Kassis E, Cathala N, Rouached H, Fourcroy P, Berthomieu P, Terry N, Davidian JC: Characterization of a selenate-resistant Arabidopsis mutant. Root growth as a potential target for selenate toxicity. Plant Physiol 2007, 143:1231-1241

18. Awazuhara M, Fujiwara T, Hayashi H, Watanabe-Takahashi A, Takahashi $H$, Saito K: The function of SULTR2; 1 sulfate transporter during seed development in Arabidopsis thaliana. Plant Physio/ 2005, 125:95-105.

19. Buchner P, Stuiver E, Westerman S, Wirtz M, Hell R, Hawkesford M, De Kok L: Regulation of Sulfate Uptake and Expression of Sulfate Transporter Genes in Brassica oleracea as Affected by Atmospheric $\mathrm{H} 2 \mathrm{~S}$ and Pedospheric Sulfate Nutrition. Plant Physiol 2004, 136:3396-3408.

20. Kataoka T, Hayashi N, Yamaya T, Takahashi H: Root-to-shoot transport of sulfate in Arabidopsis: Evidence for the role of SULTR3;5 as a component of low-affinity sulfate transport system in the root vasculature. Plant Physiol 2004, 136:4198-4204

21. Kataoka T, Watanabe-Takahashi A, Hayashi N, Ohnishi M, Mimura T, Buchner P, Hawkesford MJ, Yamaya T, Takahashi H: Vacuolar sulfate transporters are essential determinants controlling internal distribution of sulfate in Arabidopsis. Plant Cell 2004, 16:2693-2704.

22. Toufighi K, Brady SM, Austin R, Ly E, Provart NJ: The Botany Array Resource: e-Northerns, Expression Angling, and promoter analyses. Plant J 2005, 43:153-163.

23. Alonso JM, Stepanova AN, Leisse TJ, Kim CJ, Huaming C, Shinn P, Stevenson DK, Zimmerman J, Barajas P, Cheuk R, Gadrinab C, Heller C, Jeske A, Koesema E, Meyers CC, Parker H, Prednis L, Ansari Y, Choy N, Deen H, Geralt M, Hazari N, Hom E, Karnes M, Mulholland C, Ndubaku R, Schmidt I, Guzman P, Aguilar-Henonin L, Schmid M, Weigel D, Carter D, Marchand T, Risseeuw E, Brogden D, Zeko A, Crosby WL, Berry CC, Ecker JR: Genomewide insertional mutagenesis of Arabidopsis thaliana. Science 2003 301:653-657.

24. Shibagaki N, Grossman AR: The role of the STAS domain in the function and biogenesis of a sulfate transporter as probed by random mutagenesis. J Biol Chem 2006, 281:22964-22973.

25. Gallardo K, Job C, Groot SP, Puype M, Demol H, Vandekerckhove J, Job D: Proteomic analysis of Arabidopsis seed germination and priming. Plant Physiol 2001, 126:835-848.

26. Gallardo K, Job C, Groot SP, Puype M, Demol H, Vandekerckhove J, Job D: Proteomics of Arabidopsis seed germination. A comparative study of wild-type and gibberellin-deficient seeds. Plant Physio/ 2002, 129:823-837.

27. Rajiou L, Gallardo K, Debeaujon I, Vandekerckhove J, Job C, Job D: The effect of a-amanitin on the Arabidopsis seed proteome highlights the distinct roles of stored and neosynthesized mRNAs during germination. Plant Physiol 2004, 134:1598-1613.

28. Bevan M, Bancroft I, Bent E, Love K, Goodman H, Dean C, Bergkamp R, Dirkse W, Van Staveren M, Stiekema W, Drost L, Ridley P, Hudson SA, Patel K, Murphy G, Piffanelli P, Wedler H, Wedler E, Wambutt R, Weitzenegger T, Pohl TM, Terryn N, Gielen J, Villarroel R, De Clerck R, Van Montagu M, Lecharny A, Auborg S, Gy I, Kreis M, Lao N, Kavanagh T, Hempel S, Kotter P, Entian KD, Rieger M, Schaeffer M, Funk B, Mueller-Auer S, Silvey M, James R, Montfort A, Pons A, Puigdomenech P, Douka A, Voukelatou E, Milioni D, Hatzopoulos P, Piravandi E, Obermaier B, Hilbert H, Düsterhöft A, Moores T, Jones JD, Eneva T, Palme K, Benes V, Rechman S, Ansorge W, Cooke R, Berger C, Delseny M, Voet M, Volckaert G, Mewes HW, Klosterman S, Schueller C, Chalwatzis N: Analysis of $1.9 \mathrm{Mb}$ of contiguous sequence from chromosome 4 of Arabidopsis thaliana. Nature 1998, 391:485-488.

29. Sweetlove LJ, Heazlewood JL, Herald V, Holtzapffel R, Day DA, Leaver CJ, Millar AH: The impact of oxidative stress on Arabidopsis mitochondria. Plant J 2002, 32:891-904

30. Bindschedler LV, Palmblad M, Cramer R: Hydroponic isotope labelling of entire plants (HILEP) for quantitative plant proteomics; an oxidative stress case study. Phytochem 2008, 69:1962-1972.

31. Desikan R, Mackerness SA-H, Hancock JT, Neill SJ: Regulation of the Arabidopsis transcriptome by oxidative stress. Plant Physiol 2001, 127:159-172.

32. Nikiforova V, Freitag J, Kempa S, Adamikn M, Hesse H, Hoefgen R: Transcriptome analysis of sulfur depletion in Arabidopsis thaliana: interlacing of biosynthetic pathways provides response specificity. Plant J 2003, 33:633-650.

33. Maruyama-Nakashita A, Inoue E, Watanabe-Takahashi A, Yamaya T, Takahashi H: Transcriptome profiling of sulfur-responsive genes in Arabidopsis reveals global effects of sulfur nutrition on multiple metabolic pathways. Plant Physiol 2003, 132:597-605.

34. Higashi Y, Hirai MY, Fujiwara T, Naito S, Noji M, Saito K: Proteomic and transcriptomic analysis of Arabidopsis seeds: molecular evidence for successive processing of seed proteins and its implication in the stress response to sulfur nutrition. Plant $J$ 2006, 48:557-571.

35. Chen W, Singh K: The auxin, hydrogen peroxide and salicylic acid induced expression of the Arabidopsis GST6 promoter is mediated in part by an ocs element. Plant J 1999, 19:667-677.

36. Job C, Rajjou L, Lovigny Y, Belghazi M, Job D: Patterns of protein oxidation in Arabidopsis seeds and during germination. Plant Physiol 2005, 138:790-802.

37. Rajjou L, Debeaujon I: Seed longevity: Survival and maintenance of high germination ability of dry seeds. CRBiol 2008, 331:796-805.

38. Bailly C, El-Maarouf-Bouteau H, Corbineau F: From intracellular signaling networks to cell death: the dual role of reactive oxygen species in seed physiology. CR Biol 2008, 331:806-814.

39. Herbette $S$, Taconnat L, Hugouvieux V, Piette L, Magniette MLM, Cuine $S$, Auroy P, Richaud P, Forestier C, Bourguignon J, Renou JP, Vavasseur A, Leonhardt N: Genome-wide transcriptome profiling of the early cadmium response of Arabidopsis roots and shoots. Biochimie 2006, 88:1751-1765.

40. Cho UH, Seo NH: Oxidative stress in Arabidopsis thaliana exposed to cadmium is due to hydrogen peroxide accumulation. Plant Sci 2005, 168:113-120.

41. Srivastava S, Srivastava AK, Suprasanna P, D'Souza SF: Comparative biochemical and transcriptional profiling of two contrasting varieties of Brassica juncea L. in response to arsenic exposure reveals mechanisms of stress perception and tolerance. JExp Bot 2009, 60:3419-3431

42. Mascher R, Lippmann B, Holzinger S, Bergmann H: Arsenate toxicity: effects on oxidative stress response molecules and enzymes in red clover plants. Plant Sci 2002, 163:961-969.

43. Li F, Asami T, Wu X, Tsang EWT, Cutler A: A Putative Hydroxysteroid Dehydrogenase Involved in Regulating Plant Growth and Development. Plant Physiol 2007, 145:87-97

44. Baud S, Lepiniec $L$ : Regulation of de novo fatty acid synthesis in maturing oilseeds of Arabidopsis. Plant Physiology and Biochemistry 2009, 47:448-455.

45. Higgins TJ, Chandler PM, Randall PJ, Spencer D, Beach LR, Blagrove RJ, Kortt AA, Inglis AS: Gene structure, protein structure, and regulation of the synthesis of a sulfur-rich protein in pea seeds. J Biol Chem 1986, 261:11124-11130 
46. Hirai MY, Fujiwara T, Chino M, Naito S: Effects of sulfate concentrations on the expression of a soybean seed storage protein gene and its reversibility in transgenic Arabidopsis thaliana. Plant Cell Physiol 1995, 36:1331-1339.

47. Tabe L, Droux M: Limits to sulfur accumulation in transgenic lupin seeds expressing a foreign sulfur-rich protein. Plant Physiol 2002, 128:1137-1148

48. Nikiforova VJ, Kopka J, Tolstikov V, Fiehn O, Hopkins L, Hawkesford MJ, Hesse H, Hoefgen R: Systems Rebalancing of Metabolism in Response to Sulfur Deprivation, as Revealed by Metabolome Analysis of Arabidopsis Plants. Plant Physiol 2005, 138:304-318.

49. Nikiforova VJ, Bielecka M, Gakière B, Krueger S, Rinder J, Kempa S, Morcuende R, Scheible WR, Hesse H, Hoefgen R: Effect of sulfur availability on the integrity of amino acid biosynthesis in plants. Amino acids 2006, 30:173-183.

50. Ravanel S, Gakière B, Job D, Douce R: The specific features of methionine biosynthesis and metabolism in plants. Proc Nat Acad Sci USA 1998, 95:7805-7812

51. Ravanel S, Block MA, Rippert P, Jabrin S, Curien G, Rébeillé F, Douce R: Methionine metabolism in plants: chloroplasts are autonomous for de novo methionine synthesis and can import S-adenosylmethionine from the cytosol. J Biol Chem 2004, 279:22548-22557.

52. Levine RL, Mosoni L, Berlett BS, Stadtman ER: Methionine residues as endogenous antioxidants in proteins. Proc Natl Acad Sci USA 1996, 93:15036-15040.

53. Levine R, Berlett B, Moskovitz J, Mosoni L, Stadtman ER: Methionine residues may protect proteins from critical oxidative damage. Mechanisms of Ageing and Development 1999, 107:323-332.

54. Bewley JD, Black M: Seeds: Physiology of development and germination New York Plenum Press; 1994

55. Kranner I, Birtic S: Modulating Role for Antioxidants in Desiccation Tolerance. Integrative and Comparative Biology 2005, 45:734-740.

56. Bräutigam K, Dietzel L, Kleine T, Ströher E, Wormuth D, Dietz KJ, Radke D, Wirtz M, Hell R, Dörmann P, Nunes-Nesi A, Schauer N, Fernie AR, Oliver SN, Geigenberger P, Leister D, Pfannschmidt T: Dynamic Plastid Redox Signals Integrate Gene Expression and Metabolism to Induce Distinct Metabolic States in Photosynthetic Acclimation in Arabidopsis. Plant Cell 2009, 21:2715-32.

57. Fey V, Wagner R, Bräutigam K, Wirtz M, Hell R, Dietzmann A, Leister D, Oelmüller R, Pfannschmidt T: Retrograde plastid redox signals in the expression of nuclear genes for chloroplast proteins of Arabidopsis thaliana. J Biol Chem 2005, 280:5318-5328.

58. Meyer AJ: The integration of glutathione homeostasis and redox signaling. J Plant Physiol 2008, 165:1390-1403.

59. Schwarzländer M, Fricker MD, Müller C, Marty L, Brach T, Novak J, Sweetlove LJ, Hell R, Meyer AJ: Confocal imaging of glutathione redox potential in living plant cells. J Microsc 2008, 231:299-316.

60. Doyle JL, Doyle JJ: Isolation of plant DNA from fresh tissue. Focus 1990 12:13-15.

61. Chang S, Puryear J, Cairney J: A simple and efficient method for isolating RNA from pine trees. Plant Mol Biol Rep 1993, 11:113-116.

62. Wirtz M, Droux M, Hell R: O-Acetylserine (thiol) lyase: An enigmatic enzyme of plant cysteine biosynthesis revisited in Arabidopsis thaliana. J Exp Bot 2004, 55:1785-1798.

63. Gallardo K, Le Signor C, Vandekerckhove J, Thompson RD, Burstin J: Proteomics of Medicago truncatula seed development establishes the time frame of diverse metabolic processes related to reserve accumulation. Plant Physiol 2003, 133:664-82.

64. Bradford $\mathrm{M}$ : A rapid and sensitive method for the quantitation of microgram quantities of protein utilizing the principle of protein-dye binding. Anal Biochem 1976, 72:248-254.

65. Mathesius U, Keijzers G, Natera SH, Weinman JJ, Djordjevic MA, Rolfe BG: Establishment of a root proteome reference map for the model legume Medicago truncatula using the expressed sequence tag database for peptide mass fingerprinting. Proteomics 2001 1:1424-1240.

66. Gallardo K, Firnhaber C, Zuber H, Héricher D, Belghazi M, Henry C, Küster H, Thompson R: A Combined Proteome and Transcriptome Analysis of Developing Medicago truncatula Seeds: Evidence for Metabolic Specialization of Maternal and Filial Tissues. MCP 2007, 6:2165-2179. doi: 10.1186/1471-2229-10-78

Cite this article as: Zuber et al., Sultr4;1 mutant seeds of Arabidopsis have an enhanced sulphate content and modified proteome suggesting metabolic adaptations to altered sulphate compartmentalization BMC Plant Biology 2010, 10:78

\section{Submit your next manuscript to BioMed Central and take full advantage of:}

- Convenient online submission

- Thorough peer review

- No space constraints or color figure charges

- Immediate publication on acceptance

- Inclusion in PubMed, CAS, Scopus and Google Scholar

- Research which is freely available for redistribution

Submit your manuscript at www.biomedcentral.com/submit
C BioMed Central 